\title{
REFLORESCER, PERSISTIR E RESISTIR: PRÁTICAS XAMÂNICAS INDÍGENAS NA ATUALIDADE
}

\author{
Sergio Baptista da Silva \\ (UFRGS, Brasil) \\ José Glebson Vieira \\ (UFRN, Brasil) \\ Antonella Fagetti \\ (BUAP, México)
}

Originalmente, a temática da "universalidade e particularismos nos sistemas xamânicos dos povos ameríndios" foi uma proposta de simpósio apresentada à organização do $56^{\circ}$ Congresso Internacional de Americanistas, que, aceita, aconteceu em Salamanca, Espanha, em julho de 2018.

Devido ao sucesso daquele simpósio, dada a alta qualidade dos textos apresentados naquela ocasião e levando em conta a florescente e ampla ocorrência de práticas xamânicas indígenas na atualidade, seus coordenadores (Sergio e Antonella), a convite de um de seus participantes (Glebson), resolveram propor novamente a mesma temática para um número da Vivência.

Nesse sentido, estamos apresentando aos(às) leitores(as) desde diferentes e múltiplas abordagens teóricas a uma série de artigos consagrados à discussão e à compreensão de práticas e sistemas xamânicos em coletivos indígenas americanos em todas as cinco regiões brasileiras e no noroeste argentino.

Desde a tradição dos estudos antropológicos, uma variedade de enfoques foi empregada no estudo e no entendimento do xamanismo. Um deles aproxima-se desse fenômeno como um sistema cosmológico, vinculado a inúmeras práticas e saberes específicos. Nessa perspectiva, ele tem oferecido às chamadas "sociedades tradicionais" os meios para conhecer a origem da enfermidade e da adversidade, e propiciar por meio de rituais complexos o bem-estar de todos (FAGETTI, 2012). A partir dessa abordagem, seus especialistas, os xamãs, têm sido compreendidos como interlocutores e mediadores entre alteridades radicais e as pessoas de seu povo, em virtude de sua capacidade para experimentar estados não ordinários de consciência, por meio dos sonhos e do transe (FAGETTI, 2015).

Por outro lado, o xamanismo, através de distintas práticas socioculturais associadas a concepções cosmo-ontológicas, pode ser compreendido a partir das concepções de constituição e de manutenção de corpos e pessoas, bem como de suas transformações ontológicas (FAUSTO, 2001; VIVEIROS DE CASTRO, 2002; LIMA, 2005; VILLAÇA, 2005; BAPTISTA DA SILVA, 2013; 2014).

Igualmente, os fenômenos xamânicos têm propiciado inúmeras outras abordagens que podem enfocar sua relação com princípios e formas de poder (CLASTRES, 1974; CLASTRES, 1975; CHAUMEIL, 1983; SZTUTMAN, 2009; VIEIRA, 2012); com saberes vinculados à agência e ao poder de cura 
relacionados a diferentes seres existentes do cosmos (DESCOLA, 2006); com a produção de malefícios (IDOYAGA MOLINA, 1978-1979; FAGETTI, 2011-2012); com manifestações artísticas (VIDAL, 1992; VAN VELTHEM, 2003; LAGROU, 2007; MILLER, 2007; MONTARDO, 2009; BAPTISTA DA SILVA, 2011); com modos de ação cosmopolítica (DE LA CADENA, 2005; ANDRADE, 2008; HORTA PRIETO, 2014); entre muitas outras abordagens possíveis.

Tendo, portanto, como referência a riqueza e complexidade de nossa matriz disciplinar antropológica, esse número temático de Vivência reúne estudos com variados enfoques e que têm como preocupação principal explorar, do ponto de vista teórico e etnográfico, as múltiplas manifestações do xamanismo indígena no contexto contemporâneo, contribuindo na elucidação tanto da sua universalidade como dos seus particularismos, da unidade como da diversidade, das semelhanças como das diferenças entre os diversos sistemas xamânicos indígenas e suas práticas.

Como modo de apresentação deste número da Vivência e como estratégia compreensiva e descritiva dos artigos ora publicados, optamos por subdividi-los em alguns eixos ou blocos temático-analíticos, que não são totalmente autônomos e autoexcludentes entre si.

O primeiro deles aglutina uma série de artigos nos quais a dimensão cosmopolítica de práticas xamânicas são apresentadas e discutidas. A etnografia desses artigos e a reflexão de seus autores enfatizam o protagonismo dos diversos especialistas rituais em sua atuação cosmopolítica tanto interna como externamente a seus coletivos.

Nesse eixo temático-analítico incluímos os artigos de Clémentine Maréchal, de José Glebson Vieira e de Pedro Valério.

Em A práxis xamânica Kaingang na atualidade: uma cosmopolítica da floresta, Clémentine Maréchal propõe uma análise pertinente sobre o xamanismo através da descrição de diferentes expressões da práxis xamânica Kaingang que testemunham a intencionalidade dos kujà (xamãs), ao afirmarem seu protagonismo cosmopolítico tanto dentro quanto fora das suas comunidades. A autora enfrenta uma questão desafiadora no contexto contemporâneo que consiste em compreender o "reflorescimento" do xamanismo provavelmente associado a diversos fenômenos de legitimação do xamanismo como práxis dentro das próprias comunidades, e dos xamãs que tiveram suas práticas perseguidas e castigadas pelos diversos agentes coloniais e civilizatórios e que atuam hoje no sentido de recuperar seu poder enquanto liderança sócio-cosmo-política e dar continuidade às suas práticas mediante a transmissão dos seus poderes para as futuras gerações.

José Glebson Vieira, em Catimbó e Toré: práticas rituais e xamanismo do povo potiguara da Paraíba, após apresentar historicamente os Potiguara, discute a rica e complexa concepção nativa de encantado, colocando em evidência uma criatividade e reelaboração atual do sistema xamânico potiguara, no qual seus especialistas rituais - para além de deterem um saber cosmológico ao mesmo tempo específico, amplo e aberto - passam a desempenhar ações cosmopolíticas externa e internamente relevantes. No primeiro caso, atuando na visibilização dos grupos e na sua resistência, através do acionamento de uma linguagem étnica. $\mathrm{E}$, internamente, assumindo tanto a proteção da aldeia e de bem-estar de seus membros como a resolução de conflitos, por intermédio das relações estabelecidas entre os especialistas rituais e os encantados. Caminhos que conduzem, como aponta o autor, à elaboração de um "princípio de autoridade". 
No último artigo desse primeiro bloco, temos o texto de título Pensando com as florestas: uma exposição de questões do antropomorfismo à luz das palavras do xamã Davi Kopenawa, de Pedro Valério. Nele, o autor problematiza diversas questões relacionadas à prática xamânica, como o antropomorfismo, o animismo e a própria teoria antropológica. Partindo da frase "A floresta é inteligente, ela tem um pensamento", o autor propõe analisar diversas facetas presentes no livro "A Queda do Céu", como uma reflexão sobre uma contra-antropologia que se esboça pelo xamanismo e, assim, busca desenvolver "um ataque reverso à tradição ocidental, uma espécie de desconstrução reversa" que consiste em intervenções de fora para dentro, do mundo do xamã para o mundo dos napës, ou o mundo dos brancos, dos modernos e dos invasores da floresta. A floresta que foi definida pela antropologia por meio das questões da antropomorfia, ou seja, se a floresta pensa, ela deve pensar como o humano, ela deve ter algo de humano é aqui apresentada como "xamânica", levando ao que o autor denomina de curto-circuito dos dois lados separados inteiramente pelos principais e mais influentes modos de pensar/agir do ocidente. Ao dizer que a floresta pensa e é inteligente, Davi Kopenawa está promovendo a aproximação do humano com o não-humano, tornando-os próximos e parecidos demais, ligando os polos que no ocidente foram afastados para que a própria humanidade pudesse ser definida.

O segundo eixo temático-analítico agrupa artigos que evidenciam a conexão entre práticas xamânicas e a constituição de circuitos de trocas externas, com o cristianismo católico e evangélico) e de relações intra e intercomunitárias e que aborda vínculos entre práticas xamânicas e transformações ontológicas. Nele, incluímos os textos de Ugo Maia Andrade e Maria Eugênia Flores, bem como o de Bruno Aroni.

Em Xamanismo e redes de relações interindígenas: Amazônia e Nordeste brasileiro, Ugo Maia Andrade traz uma interessante e instigante reflexão comparativa entre duas regiões (submédio Rio São Francisco - divisa BA/PE/ $\mathrm{AL}$ - e o baixo Rio Oiapoque - fronteira Brasil/Guiana Francesa). Nessas regiões, há importantes relações de trocas interindígenas baseadas no xamanismo, nas quais são constituídos circuitos de trocas xamânicas que vão da complementaridade ritual à dissensão provocada por acusações de feitiçaria, modulando relações políticas intra e intercomunitárias. São as trocas empreendidas em tais circuitos que permitem assinalar as permutas (positivas e negativas) enquanto marcadoras e constituidoras do próprio xamanismo nos dois contextos etnográficos. Além das permutas positivas de conhecimento, cantos e iniciação, e das permutas negativas de agressões entre pajés, acusações de feitiçaria, no contexto do submédio do rio São Francisco, é marcante o empenho das permutas de apoio político, decorrente, como mostra o autor, dos movimentos por identidade, em que os desempenhos rituais se tornaram o principal componente da "expressão da indianidade", sendo função ensejada (e desejada) pelo próprio Estado.

Maria Eugenia Flores, no seu artigo intitulado Los guaraní y los chané en el ahora. Chamanismo, religión y etnopolitica en el noroeste argentino, traz e discute muitos elementos para a compreensão etnohistórica e antropológica dos especialistas rituais dos sistemas xamânicos ontológicos do complexo chiriguano-chané, composto por uma rica e variada população formada por coletivos indígenas ligados às famílias linguísticas arawak e tupi-guarani em uma região que se estende desde o Izoso boliviano até o noroeste argentino. A autora traz inúmeros exemplos das relações entre diferentes denominações de xamãs e alteridades extra-humanas, que são seres que lhes outorgam poder e conhecimentos. A autora, igualmente, aborda a influência das missões evangelizadoras na região, destacando a presença de xamãs e de suas práticas nesses ambientes e enfatizando a abertura desses sistemas xamânicos para "aprender 
a manejar o poder dos outros". Ao finalizar seu artigo, Maria Eugenia Flores analisa, a partir dessa perspectiva, os coletivos indígenas nos quais realizou trabalho de campo no norte argentino, "comunidades que se auto reconocen como guaraníes, pero donde viven en plurietnicidad con familias chané, izoseñas, simbas, ava y tapietes", assinalando a importância de futuros trabalhos etnográficos entre essas populações, especialmente como objetivo de aprofundar o estudo das relações intersubstanciais que esses especialistas rituais têm com outras espécies e alteridades com as quais convivem" nesses contextos de transfiguração e "contacto intercultural con el cristianismo católico y evangélico".

Bruno Oliveira Aroni, em Intersecções entre materialidades e sonoridades na construção da categoria iyamaka Paresi-Haliti, propõe demonstrar como a fabricação material e a produção musical constituem tecnologias rituais relevantes entre os Paresi-Haliti e são capazes de garantir relações harmônicas entre os haliti e outras entidades não-humanas concebidas em sua cosmologia. O autor adota uma postura interessante acerca da discussão sobre a chamada ficção fetichista que consiste na atribuição de um pensamento animista aos Paresi em relação às flautas. Para ele, é necessário descartar tal ficção, o que significa levar em conta a categoria iyamaka, que designa o conjunto de aerofones rituais proibidos à visão das mulheres e associados a poderosos espíritos, aos quais são dedicados festivais e oferendas, genericamente denominados flautas secretas ou sagradas. $\mathrm{O}$ autor propõe que na referida categoria pode-se encontrar uma configuração musical xamânica, em que a produção musical constitui tanto um meio de socializar relações com várias categorias do outro. Entre os Paresi, as flautas são produzidas segundo técnicas irrevogáveis que envolvem a sua fabricação/ materialização e posteriormente sua nutrição que consiste na necessidade de alimentá-las constantemente, a fim de não gerar a sua indisposição diante de seus donos. A nutrição das flautas constitui uma tecnologia que mobiliza trabalhos e depende de uma série de processos materiais de transformação e negociações subjetivas, uma vez que é por meio dela que se possibilita um controle positivo sobre o potencial de agência contido nas flautas.

Por fim, uma palavra sobre nossa capa.

Como a presente edição temática da revista Vivência trata de persistências, florescimentos e resistências vinculadas a práticas xamânicas, nada mais oportuno do que trazer uma pintura do artista indígena Jaider Esbell. Do povo Makuxi do Amapá, Jaider tem se destacado no cenário contemporâneo dentro da chamada arte indígena contemporânea, sendo esta definida pelo próprio Jaider "como um dos lugares centrais e estratégicos para se perceber no mundo, perceber o mundo, os mundos, as imundícies e as maravilhas do talvez. [...] lugar de encontro do momento" (ESBELL, 2016). "Pata Ewa'n - O coração do mundo" (2016) é uma pintura acrílica sobre tela e juntamente com outras produções venceu o Prêmio Pipa online de 2016. A produção artística de Jaider, como está descrita no Prêmio Pipa 2016:

Enviesa ainda mais o caos das expressões humanas e não humanas. As forças da floresta, dos seres, emanam da arte do filho do tempo, de todas as influências: ancestralidade, conhecimento, memória, diálogos, plasticidade contemporânea, política global, o ser local, xamanismo visual, poder. Palavra, imagem, som, silêncio - comunicação em todas as linguagens. A arte de Esbell exige, para além dos sentidos, imersão. (ESBELL, 2016).

Jaider Esbell também se destaca como escritor e arte-ativista e produtor cultural. Em um texto que pode ser encontrado na página da exposição "O xamâ devolve a vida"1, Jaider expressa a relação e o lugar do xamanismo nas encruzilhadas com o "tempo presente", o antropoceno, a destruição das 
florestas, graças a busca desenfreada pela mineração e os esbulhos dos territórios indígenas.

Eis que estamos vivendo agora, todos nós, o ápice do tempo antropoceno. Se não há futuro para nós, não haverá futuro para ninguém. Esse tempo presente é a última chance que temos para celebrar a vida, a vida com dignidade para todos; homens, animais, minerais, espíritos. Essa carta tem a intenção de convidar toda a humanidade para pensarmos juntos o futuro comum de nossas próximas gerações e isso é mesmo urgente. Eu, de minha parte, represento, em uma leitura poética, profética, a última ligação dos seres humanos com a essência da natureza, ou seja, a vida em sua origem. Eu também represento o pensamento dos anciãos de toda a terra e não devemos suportar por vocês essa grande guerra, sozinhos. Eu vou além pois posso ouvir a voz dos que antes viveram e que nos alertaram que a arte é a nossa grande chance de falar de um modo mais verdadeiro. Eu venho de lá, dos cantos mais remotos das florestas virgens. É de lá que venho, da grande Amazônia, de onde os "selvagens" correm para todos os lados sem entender de onde vem o fim do mundo. O fato é que eles sabem, pois podem ver a catástrofe por meio de seus xamãs. Com muita súplica nos convidam a segurar o céu sobre nossas cabeças com o melhor de nossa sabedoria, a sensatez. Lá, nas florestas virgens, as crianças perdem suas mães, seus pais, irmãos e ficam sozinhas morrendo lentamente vagando envenenadas com o lixo da modernidade por todos os lados. O lixo da modernidade que vocês, os homens donos dos bancos, donos do poder que é o dinheiro alimentam com suas poderosas estruturas de destruição que nunca param. Todo o ouro que antes e ainda mais agora são retirados da terra podem hoje formar um grande espelho e lhes mostrar. O brilho dos diamantes, da prata, forma agora um grande espelho onde pode mostrar para quem pode ver os rastros de sangue que a ganância deixa por onde passa. Sabemos que é muito simples retroceder. Limpar a natureza de todo lixo industrial, limpar o espírito dos homens desse sentimento morto, frio e insensível que esta oculto nestes prédios tão distantes de nossa realidade. Eu posso ser você nesse caminho da vida mas não podemos ser natureza uma vez que a negamos e ficamos cada vez mais distantes. Ouvir o clamor mundial por justiça social. Aceitar de uma vez por todas que o aquecimento global é uma realidade pois as águas não mentem. $\mathrm{O}$ vento não mente, o clima não mente. Falamos sim pelos elementos da natureza já que nós meramente humanos não temos mais direito a nossa própria voz. Que haja sensatez e muito mais tolerância. Que considerem tecnicamente a possibilidade de investir na estrutura universal pois o amor de vocês foi investido na guerra e a felicidade de vocês está em fazer as pessoas sofrerem em todos os cantos. Não há outro modo de viver por mais que se tenha dinheiro. Devemos sim, aquecer a terra com amor, esse nobre valor desvalorizado. Devemos sim cobrar por justiça e entender que a educação pode mudar o rumo e apontar outro prumo pra que atravessemos o mundo e sigamos vitoriosos deixando tesouros de paz e harmonia, uma forma simples e pura de sermos gratos pelo universo que tudo nos deu e que está muito perto de tudo nos tirar. Somos iguais em tudo e por tudo digo que não queremos, que não merecemos ficar com o lado pobre desta riqueza comum. Aqui deixo mais uma vez saber que esta voz é uma voz da arte que me criou para andar no mundo mostrando de todas as formas o invisível, isso que não tá na matéria, mas que a sustenta. Essa carta é uma representação, eu cá como povo indígena e você aí como o capitalismo cruel e sem coração. Trago um pouco de luz para você. É vermelho nosso sangue, azul a nossa água e não há mais tempo para tanto sofrimento. Lutem conosco, vocês têm poder, assim como nós (JAIDER ESBELL).

Desejamos uma ótima leitura a todo/as. 


\section{NOTAS}

${ }^{1}$ Texto de apresentação da exposição realizada pela Estação Casa Amarela na Galeria Flamboyant, 4 a edição, Caçapava-SP. De 11 de jun à 27 de set de 2019. Disponível em: http://estacaocasaamarela.com.br/o-xama-devolve-a-vida/. Acesso em: 04 mai. 2020.

\section{REFERÊNCIAS}

ANDRADE, Ugo M. Memória e Diferença: Os Tumbalalá e as redes de trocas no submédio São Francisco. São Paulo: Humanitas; FAPESP, 2008.

BAPTISTA DA SILVA, Sergio. Iconografia e ecologia simbólica: retratando o cosmos guarani. In: PROUS, A.; LIMA, T. A (org.). Ceramistas Tupiguarani: eixos temáticos. Belo Horizonte: Superintendência do IPHAN em Minas Gerais, 2011, p. 115-148.

. Cosmo-ontológica mbyá-guarani: discutindo o estatuto de 'objetos' e 'recursos naturais'. Revista de Arqueologia, v. 26, n. 1, p. 42-54, 2013.

. Cosmo-ontologia e xamanismo entre coletivos kaingang. In: FLECK, Eliane Cristina Deckmann (org.). Religiões e religiosidades no Rio Grande do Sul: manifestações da religiosidade indígena. São Paulo: ANPUH, 2014. v. 3, p. 69-96. (Coleção Memória \& Cultura NEMEC/PPGH).

CHAUMEIL, Jean-Pierre. Voir, savoir, pouvoir: le chamanisme chez les Yagua du Nord-Est péruvien. Paris: Ed. de l'École des Hautes Études en Sciences Sociales, .

CLASTRES, P. A sociedade contra o Estado: pesquisas de antropologia política. São Paulo: Cosac Naify, 2003 [1974].

CLASTRES, H. La terre sans mal: le prophétisme tupi-guarani. Paris:

Éditions du Seuil, 1975.

COSTA, Ana Cristina Popp da. Há erami rãema jaiko: vamos levando a vida desse jeito. Dissertação (Mestrado em Programa de Pós-graduação em Antropologia Social-PPGAS) - Universidade Federal do Rio Grande do Sul,

DE LA CADENA, Marisol. Earth Beings: Ecologies of Practice Across Andean Worlds. Durham e Londres, Duke University Press, 2015.

DESCOLA, Philippe. As lanças do crepúsculo: relações jivaro na alta Amazônia. São Paulo, Cosac Naify, 2006 [1993].

ESBELL, Jaider. Pipa Prêmio, 2016, Disponível em: https://www.premiopipa.com/pag/jaider-esbell. Acesso em: 30 nov. 2019.

FAGETTI, Antonella. Nexikole y texoxa: el daño por brujería como categoría nosológica nahua. AM. Rivista della Società italiana di Antropologia médica. Numeri 2829, ottobre 2010 3021, p. 123151, 20112012.

. Cuando "habla" la semilla: adivinación y curación con enteógenos en la Mixteca oaxaqueña. Cuicuilco, v.19, n. 53, p. 229-255, eneroabril, 2012. as. El trance y los sueños enel devenir del chamán. México: Siglo XXI/Instituto de Ciencias Sociales y Humanidades-BUAP, 2015.

HERCKMAN, Elias. 1886[1639]. Descripção geral da Capitania da Parahyba. Revista do Instituto Archeologico e Geographico Pernambucano, tomo V, n. 31, p. 239-288, 2015. Recife: Typographia Industrial. Disponível em: http://biblio.etnolinguistica.org/herckman_1886_parahyba. Acesso em: 26 nov. 2019.

HORTA PRIETO, Ana. Tejiendo entre redes diversas: reflexiones a partir de una etnografía multisituada con los pueblos indígenas de la Sierra Nevada de Santa Marta, Caribe colombiano. Espaço Ameríndio, Porto Alegre, v. 8, n. 1, p. 135-161, jan./jun. 2014. 
IDOYAGA MOLINA, Anatilde. La bruja pilagá. Scripta Ethnologica, vol. V, parte 2, p. 95-117, 1978-79.

LAGROU, Els Maria. A fluidez da forma: arte, alteridade e agência em uma sociedade amazônica (Kaxinawa, Acre). Rio de Janeiro, Topbooks, 2007.

LIMA, Tânia Stolze. Um peixe olhou para mim: o povo Yudjá e a perspectiva. São Paulo: Editora UNESP: ISA; Rio de Janeiro: NuTI, 2005.

MONTARDO, Deise Lucy Oliveira. Através do mbaraká: música, dança e xamanismo guarani. São Paulo: EDUSP, 2009.

MILLER, Joana. As coisas: os enfeites corporais e a noção de pessoa entre os Mamaindê (Nambiquara) - Tese de doutorado. Rio de Janeiro, PPGAS, Museu Nacional, UFRJ, 2007.

PRADELLA, Luiz Gustavo Souza. Entre os seus e os outros: horizonte, mobilidade e cosmopolítica guarani. 2009. Dissertação (Mestrado em Programa de Pós-graduação em Antropologia Social-PPGAS) - Universidade Federal do Rio Grande do Sul.

PRATES, Maria Paula. Dualidade, pessoa e transformação: relações sociocosmológicas mbyá-guarani no contexto de três aldeias no RS. Dissertação (Mestrado em Programa de Pós-graduação em Antropologia Social-PPGAS) - Universidade Federal do Rio Grande do Sul, Conselho Nacional de Desenvolvimento Científico e Tecnológico,

. Da instabilidade e dos afetos: pacificando relações, amansando Outros. Cosmopolítica mbyá-guarani (Lago Guaíba/RS-Brasil). Tese (Doutorado em Programa de Pós-graduação em Antropologia Social-PPGAS) - Universidade Federal do Rio Grande do Sul, Coordenação de Aperfeiçoamento de Pessoal de Nível Superior, .

SZTUTMAN, Renato. Religião nômade ou germe do estado? Pierre e Hélène Clastres e a vertigem tupi. Novos estudos CEBRAP, n. 83, São Paulo, março 2009.

TEMPASS, Mártin César. Orerémbiú: a relação das práticas alimentares e seus significados com a identidade étnica e a cosmologia Mbyá-Guarani. 2005. Dissertação (Mestrado em Programa de Pós-graduação em Antropologia Social) - Universidade Federal do Rio Grande do Sul, Coordenação de Aperfeiçoamento de Pessoal de Nível Superior.

. "Quanto mais doce, melhor": um estudo antropológico das práticas alimentares da doce sociedade mbyá-guarani. 2010. Tese (Doutorado em Programa de Pós-graduação em Antropologia Social-PPGAS) - Universidade Federal do Rio Grande do Sul, Conselho Nacional de Desenvolvimento Científico e Tecnológico.

VAN VELTHEM, L. O belo é a fera: a estética da produção e da predação entre os Wayana. Lisboa: Museu Nacional de Etnologia/Assírio \& Alvim, 2003.

VIDAL, Lux B. Iconografia e grafismos indígenas, uma introdução. In: Vidal, L. (org.). Grafismo indigena. São Paulo: Studio Nobel, Fapesp e Edusp, 1992.

VIEIRA, José Glebson. Amigos e competidores: política faccional e feitiçaria nos Potiguara da Paraíba. 1. ed. São Paulo: Humanitas, 2012.

VILLAÇA, Aparecida. Chronically unstable bodies. Journal of the Royal Anthropological Institute, n. 11, p. 445-464, 2005.

VIVEIROS DE CASTRO, Eduardo. Perspectivismo e multinaturalismo na América indígena. In: Viveiros de Castro. A inconstância da alma selvagem - e outros ensaios de antropologia. São Paulo, Cosac \& Naify, p. 345-399, 2002. 